Article

\title{
Teachers' Belief and Efficacy Toward Inclusive Education in Early Childhood Settings in Korea
}

\author{
Sukkyung You ${ }^{1} \oplus$, Eui Kyung Kim $^{2}$ and Kyulee Shin ${ }^{3, *}$ \\ 1 College of Education, Hankuk University of Foreign Studies, 270 Imun-dong, Dongdaemun-Gu, \\ Seoul 130-791, Korea; skyou@hufs.ac.kr \\ 2 Department of Psychology, North Carolina State University, Raleigh, NC 27695, USA; ekim7@ncsu.edu \\ 3 College of Liberal Arts, Anyang University, 22, Samdeok-ro 37beon-gil, Manan-gu, Anyang-si, \\ Gyeonggi-do 430-714, Korea \\ * Correspondence: kyuleeshin@anyang.ac.kr
}

Received: 1 February 2019; Accepted: 8 March 2019; Published: 12 March 2019

check for updates

\begin{abstract}
In the literature, teacher self-efficacy has been found to increase teachers' effective teaching strategies and students' positive learning outcomes in inclusive education, which highlights the importance of identifying and fostering factors associated with increased self-efficacy. Thus, the purpose of the current study was to examine the relations between teachers' demographic and background variables (i.e., age, teaching experience, and training experience), teachers' beliefs toward inclusive education, and teachers' self-efficacy. Specifically, this study aimed to test the mediating effects of teachers' beliefs toward inclusive education on the relations between teachers' demographic and background variables and their self-efficacy using structural equation modeling (SEM). Teacher beliefs toward inclusive education included the effectiveness of inclusive education on the social and cognitive development of children with disabilities and on non-disabled students' understanding of the needs of children with disabilities. Results indicated that whereas teacher age and teaching and training experiences had no direct relations with teachers' self-efficacy in inclusive education, teaching and training experiences had significant indirect relations with their self-efficacy through their beliefs toward inclusive education. Implications and future directions are discussed.
\end{abstract}

Keywords: teacher belief; self-efficacy; inclusive education; early childhood

\section{Introduction}

The number of inclusive education settings where students with and without disabilities are educated together has been increasing worldwide over the last few decades. A non-government organization, Inclusion International [1], has argued that inclusive education is one of the rights of people with disabilities, and that their rights are protected when every person participates in the education process without any exclusions. Inclusive education is meaningful because it can eradicate discrimination and provide every student with an equal opportunity for education [2,3].

Ample evidence exists on the positive influences of inclusive education on both students with and without disabilities. According to Lee and Kim [4], children without disabilities interact with those with disabilities more often in inclusive educational settings and, thereby, learn to take responsibility for other people's needs and have the ability to understand diversity. Especially, early childhood is a period when children have not yet developed strong stereotypes about other people, and is therefore regarded as the most appropriate developmental stage to develop accurate understanding of, and positive beliefs toward, disability. In inclusive education, children with and without disabilities can learn from each other and accept and respect diversity [4]. 
Nevertheless, numerous difficulties have been reported when attempting to effectively implement inclusive education in South Korea. The South Korean government announced its goal to expand the support for inclusive education by enacting the 2007 Early Childhood Special Education Law. Previous research on inclusive education primarily focused on the benefits of inclusive education such as positive academic or emotional development of children with and without disabilities in inclusive educational settings [5]. However, although teachers are important individuals who actively organize and use strategies to serve students with and without disabilities in the same educational settings [6], little research has been conducted on the beliefs of teachers regarding the benefits of inclusive education.

Among previous studies on teacher effectiveness, teachers' self-efficacy has long been pointed out as an important factor that improves their teaching effectiveness. For instance, students of self-efficacious teachers reported higher levels of academic achievement and academic adjustment $[7,8]$. Similarly, it has been argued that teacher self-efficacy is necessary to succeed in educating both children with and without disabilities in inclusive educational settings [8,9]. Teacher self-efficacy can improve their efforts to improve teaching skills and behaviors, in turn leading to stronger belief in their ability as a teacher [10]. Self-efficacy among teachers, therefore, influences their teaching efficiency, behaviors, and beliefs in the classroom [11].

Currently, early childhood education in South Korea lacks systematic contents and methods, so that teachers have a high degree of flexibility. Therefore, teachers make important decisions about children's learning based on their beliefs, which are influenced by their training and teaching experiences [12]. Considering previous research emphasizing teachers' beliefs towards inclusive education as a determinant of the success of inclusive education [11,13], it is necessary to investigate the current beliefs of Korean teachers towards inclusive education, and the factors related to their beliefs. Additionally, this study analyzes the relationship between teachers' beliefs towards inclusive education and their self-efficacy.

\section{Literature Review}

\subsection{Inclusive Education in South Korea}

Inclusive education refers to the school-wide approach to delivering support and education to students with disabilities in general education settings alongside those without disabilities [14], which has been a surging educational movement in South Korea [15].

A recent study by Kim [16] counted 85,012 children with disabilities in South Korea, of whom $29.3 \%(N=24,932)$ were attending special education schools and $70.7 \%(N=60,080)$ schools that implement inclusive education. Of the latter, $74 \%$ were learning in special education classes, and $26 \%$ ( $N=15,621$; i.e., only $18.4 \%$ of all children with disabilities) were learning in general education classes with those without disabilities. These outcomes indicate that although the number of students in inclusive educational settings has increased in South Korea, most of them still attend special education classes comprising exclusively students with disabilities. The implementation of inclusive education, in which students with varying abilities are taught together in one classroom, has only been attained for less than a fifth of all children with disabilities.

As positive aspects of inclusive education were frequently reported by previous studies conducted (e.g., [17]), the necessity and importance of inclusive education for children with disabilities have become a crucial topic in South Korea. Accordingly, Korean laws and policies have recognized and reflected the importance of inclusive education since the 1990s, resulting in a rapid implementation of inclusive education in educational practice [4]. However, although these legal changes discuss financial support for inclusive classroom teachers, they have failed to provide specific guidelines for teachers to run inclusive education programs [18]. Considering that teachers may need to make important decisions regarding the implementation of inclusive education without clear guidance, it is critical to understand teachers' perspectives and self-efficacy related to inclusive education. 


\subsection{Teacher Background Factors and Beliefs Towards Inclusive Education}

Teachers' background variables such as such as their age, teaching experience with children with disabilities, and training in pedagogy have been found to play significant roles in teachers' perceptions of inclusive education [6,19]. For example, depending on teachers' experience in inclusive education, the teaching skills they select to use and their perceptions of inclusive education may greatly vary, which may ultimately affect the success of inclusive education. In fact, there is evidence that teachers who had more opportunities to interact with children with disabilities during their teacher training period tended to support and view inclusive education positively [20]. Additionally, Lee, Yeung, Tracey, and Barker [21] found a positive correlation between teachers' experience with children with disabilities and their positive perception of inclusive education. It was also found that Korean teachers who had four to six years of teaching experience showed more positive perceptions toward inclusive education than those with less years of teaching experience [4].

Previous studies have emphasized the development and expansion of teacher training programs that facilitate the acquisition of knowledge and skills for inclusive education among teachers to increase their positive perceptions towards inclusive education [19]. Kim and Chung [22] found that teachers reported the greatest need for more training for educating children with disabilities in order to successfully implement inclusive education. Furthermore, Kim [16] similarly found that early education teachers reported wanting to receive more direct training and support from special education teachers and institutions. In fact, workshops, practical trainings, seminars, and teacher training sessions about children with disabilities were found to improve teachers' positive perception of inclusion and the rate of agreement about the importance of inclusive education [4]. Additionally, other studies demonstrated that teacher training and education focusing on enhancing teachers' knowledge and positive beliefs about inclusive education were related to their improved ability to meet the special needs of children with disabilities [20,23], supporting the importance of providing practical training and support for teachers in inclusive education.

Another teacher variable investigated for its relationship with teachers' perceptions toward inclusive education is age, based on the belief that teacher age may act as an important factor influencing their beliefs toward more recent educational practices. However, inconsistent results have been reported. For instance, Schimidt and Vrhovnik [24] concluded that teachers in their 20s have more positive beliefs towards inclusive education than those in their 30s, 40s, and 50s in Slovenia. However, other studies $[6,25]$ reported that there is no significant correlation between teacher age and their perceptions. In an attempt to reconcile the inconsistent findings of previous research, this study investigates whether teachers' age has an effect on their beliefs towards inclusive education.

Many studies have argued that the positive beliefs of the teachers towards inclusive education play a significant role in the successful implementation of inclusive education $[14,26]$. The positive effects of inclusive education for both children with and without disabilities may be divided into their improved social and cognitive development and improved understanding of children with disabilities by those without disabilities. According to the study conducted by Kim and Cho [27] in which six early childhood inclusive education teachers were subjected to in-depth interviews, the improved social and cognitive development of children with disabilities was pointed out by the teachers as one of the positive aspects of inclusive education. Specifically, teachers reported that children with disabilities developed positive social behaviors and skills through having frequent interactions with their peers without disabilities and gained confidence and a sense of achievement. Moreover, teachers reported that through inclusive education, children without disabilities developed a higher level of understanding of the needs of children with disabilities and felt more comfortable when interacting with them.

\subsection{Teacher Beliefs and Self-Efficacy in Inclusive Education}

According to Bandura, self-efficacy means the assessment of one's own ability to fulfil certain tasks [28]. Teachers' self-efficacy can be understood as teachers' belief or conviction that they can 
have an influence on how well the students learn, even those who may be considered difficult or unmotivated $[29,30]$. Among the studies that examined the self-efficacy of teachers, Tschannen-Moran and Hoy [31] stated that teacher self-efficacy has a positive influence on students' academic achievement, motivation, and self-efficacy. In addition, teachers with high self-efficacy made more efforts to improve their teaching skills and positive classroom management strategies, and showed more flexibility when accepting and trying out new ideas and teaching methods. Contrarily, teachers with low self-efficacy reported spending more time on tasks irrelevant to learning and were found to use less effective teaching methods, which in turn impeded the students' learning [17,32]. Therefore, teacher self-efficacy is believed to play a significant role in the way they educate their students in inclusive educational settings [33]. However, there is a current lack of research examining teacher self-efficacy as a main variable in inclusive educational settings [32].

Recognizing the relevance of teacher self-efficacy on the success of inclusive education [34], previous studies tried to discover the factors that increase teacher self-efficacy. For example, Lohrmann and Barnbara [35] explained that teachers perceived themselves to be more effective when they received relevant training and education and had successful teaching experience in inclusive educational settings. Choi [36] also described teacher self-efficacy as being an internal variable that is not fixed but flexible, and that can be reinforced by the training and support they receive and teaching experience.

In addition to teacher educational backgrounds, teachers' positive perceptions about inclusive education have been found to influence their self-efficacy teaching inclusive education classes. For example, Hong and colleagues [37] found a positive correlation between teachers' positive beliefs towards inclusive education and their self-efficacy. Teachers who believed in and showed positive beliefs toward inclusive education for children with developmental disabilities tended to have a higher level of self-efficacy regarding their ability to run inclusive education classrooms. Specifically, teacher self-efficacy with regard to teaching increased when teachers improved their knowledge and skills in inclusive education, had an opportunity to have successful teaching experience in inclusive education, and developed positive beliefs towards inclusive education $[9,38]$. These results suggest that teachers' positive beliefs toward inclusive education may act as a mediator on the relationship between teacher experiences and self-efficacy related to inclusive education.

Han [39] investigated the perception of teachers and parents of early childhood inclusive education and found that teachers reported low levels of self-efficacy when leading inclusive education, despite the increasing attention given to inclusive education in South Korea. Thus, the current study aims to investigate the mediating effects of teacher beliefs towards inclusive education on the relationship between teacher demographic and educational predictors and teacher self-efficacy. Specifically, we set the following research questions:

1. Are teacher demographic and educational factors, including age, training experience, and teaching experience, significantly associated with teachers' positive beliefs about inclusive education?

2. Are teachers' positive beliefs about inclusive education associated with their self-efficacy in inclusive education classrooms?

Understanding the relationships between these factors will help educators and policy makers develop appropriate strategies to improve the quality of education provided to children with and without disabilities in inclusive education classrooms.

\section{Methods}

\subsection{Participants}

The study participants were 190 nursery center teachers who were teaching in inclusive childcare facilities in Seoul. The types of classrooms taught by the participants included special education classes teaching children with disabilities (54.69\%), general education classes teaching children with and without disabilities $(22.66 \%$ ), and inclusive classes teaching children with and without disabilities 
(22.66\%). The mean age of the sample was 28.87 years ( $\mathrm{SD}=4.97$ years) $(84.3 \%$ female). Regarding highest educational attainment, $50.4 \%$ had a bachelor's degree, $43.8 \%$ a master's degree, and $5.8 \%$ a doctorate.

\subsection{Compliance with Ethical Standards}

Ethical approval: All procedures performed in studies involving human participants were in accordance with the ethical standards of the institutional and/or national research committee and with the 1964 Helsinki Declaration and its later amendments or comparable ethical standards.

Informed consent: Informed consent was obtained from all individual participants included in the study.

\subsection{Procedure}

Participants received an information sheet explaining the study's aims and objectives and the survey by mail or by personal visit. The study was conducted in March and April 2017. The teachers were informed not to write their names on the questionnaire for the sake of anonymity. Participants were given paper and pencil surveys to be completed.

\subsection{Measures}

Teachers' beliefs about inclusive education. This scale contains 18 items from the Teachers' Beliefs about Inclusive Education Scale (TBIS [40]) (see Appendix A). The TBIS consists of three sub-factors, each of which comprises 6 items. Specifically, the three sub-factors represent the teachers' beliefs about the effects of inclusive education on (a) Disabled Children's Social Skill Development, (b) Disabled Children's Cognitive Ability Development, and (c) Non-disabled Children's Understanding of Disabled Children. The teachers reported how they felt about the effectiveness of inclusive education with items such as "I believe that inclusive education can significantly affect disabled students' cognitive abilities." The teachers rated their answers on a five-point Likert scale $(1=$ not at all, $5=$ very true $)$. The TBIS has shown good reliability and validity for Korean teachers [36,41]. The internal consistencies of all three sub-factors were acceptable in the study sample (Cronbach's $\alpha=0.73,0.70$, and 0.79 , respectively).

Teacher efficacy. Teachers' self-efficacy can be understood as teachers' belief or conviction that they can influence how well the students learn, even those who may be considered difficult or unmotivated. Teacher efficacy was assessed using the Teachers' Sense of Efficacy Scale [31], which consists of twelve items using a 5-point Likert scale from 1 (nothing) to 5 (a great deal). The scale includes items such as "How much can you do to get students to believe they can do well in school work?" This scale has shown good reliability and validity for Korean teachers [26,42]. The Cronbach's alpha coefficient for the current sample was 0.74 for this scale.

Teachers' demographic and educational variables. Participants provided information regarding their demographic and educational factors, including age, teaching experience, and training experience ( $1=$ having completed an intensive courses on special education training).

\subsection{Data Analysis}

Structural equation modeling (SEM) was used to assess the hypothesized structural relationships among the latent variables (see Figure 1$)$. The study sample $(N=190)$ was sufficiently large for SEM analyses to be applied given that a minimum sample size of 100 or 200 [43] and 10 cases per variable are required to conduct SEM [44]. In testing SEM, missing values were dealt with a full information maximum likelihood (FIML). Model fit was assessed based on several criteria: non-normed fit index (NNFI) [45], comparative fit index (CFI) [46], and root mean square error of approximation (RMSEA) [47]. Values lower than 0.08 for the RMSEA and values close to 0.95 for the NNFI and CFI were used to determine a good-fitting model. All analyses were conducted using Amos 23.0. 


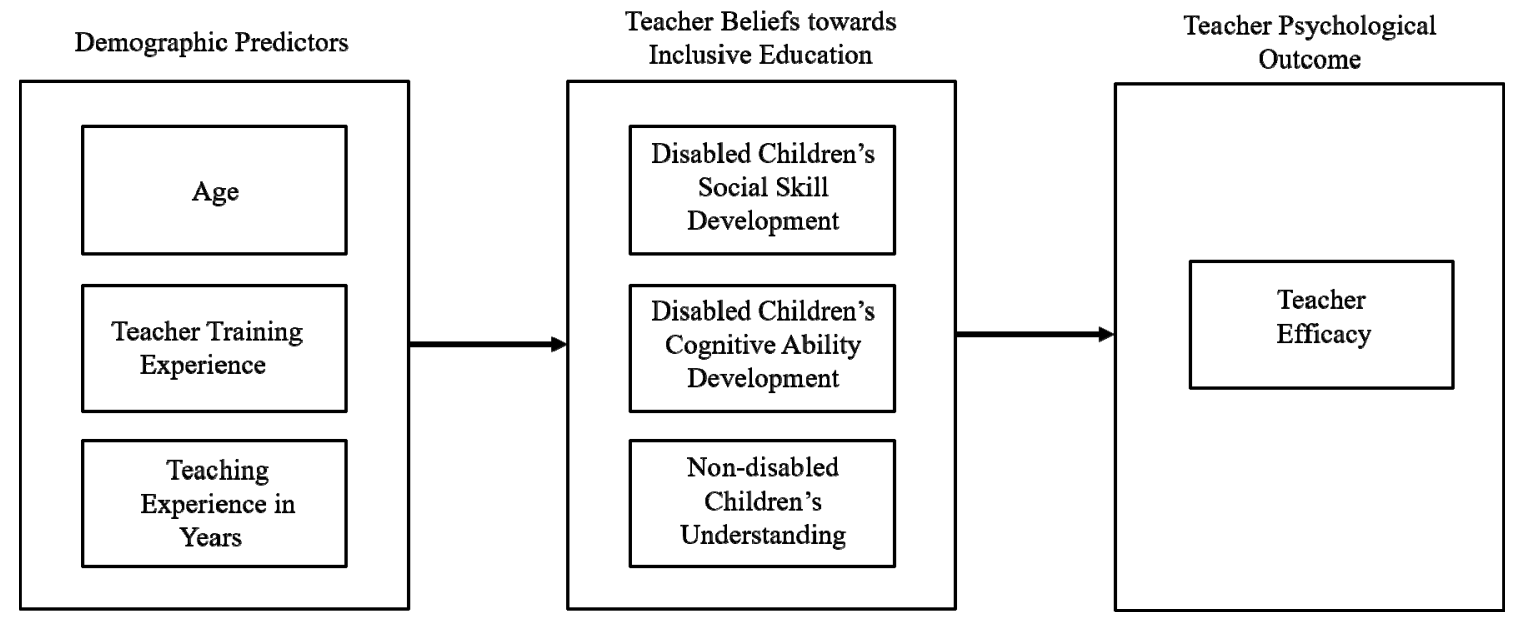

Figure 1. Theoretical framework of teacher beliefs and teacher efficacy.

\section{Results}

\subsection{Descriptive Statistics}

The correlations, mean, and standard deviation of the variables in the study are provided in Table 1. According to the guidelines of severe non-normality (i.e., skewness $>3$; kurtosis $>10$ ) proposed by Curran, West, and Finch [48], the normality assumption of all the variables was well met, where the skewness values were less than 3 and kurtosis values were less than 10.

Table 1. Descriptive Statistics for Study Variables.

\begin{tabular}{|c|c|c|c|c|c|c|c|}
\hline & 1 & 2 & 3 & 4 & 5 & 6 & 7 \\
\hline 1. Teacher's age & & & & & & & \\
\hline 2. Training experience & 0.05 & & & & & & \\
\hline 3. Teaching experience in years & $0.18 *$ & $0.44 *$ & & & & & \\
\hline 4. Disabled children's social skill development & 0.01 & $0.26 *$ & $0.37 *$ & & & & \\
\hline 5. Disabled children's cognitive ability development & 0.01 & $0.27 *$ & 0.33 * & $0.67 *$ & & & \\
\hline $\begin{array}{l}\text { 6. Non-disabled children's understanding of disabled } \\
\text { children }\end{array}$ & 0.08 & $0.26 *$ & $0.29 *$ & $0.49 *$ & $0.47^{*}$ & & \\
\hline 7. Teacher self-efficacy & 0.09 & $0.27 *$ & $0.24 *$ & $0.41 *$ & $0.40 *$ & $0.44 *$ & \\
\hline M & 28.87 & $55 \%$ & 3.98 & 3.90 & 3.81 & 3.79 & 4.06 \\
\hline SD & 4.97 & & 1.19 & 0.51 & 0.53 & 0.43 & 0.45 \\
\hline
\end{tabular}

\subsection{Testing the Mediation Models}

We tested two mediation models (i.e., partial and full mediation models). The partial mediation model yielded an overall $\chi^{2}(158)$ value of 263.07, with CFI $=0.923$, NNFI $=0.903$, and RMSEA $=0.067$, and the full mediation model yielded an overall $\chi^{2}(161)$ value of 269.33 , with CFI $=0.969$, NNFI =0.966, and RMSEA $=0.052$. The full mediation model displayed a better fit for the sample. The standardized parameter estimates for this model are presented in Figure 2.

Teacher training experience had a significant direct relationship with their beliefs about the positive impacts of inclusive education on disabled students' social development $(\beta=0.17, p<0.05)$ and on non-disabled students' understanding of the unique needs of disabled students $(\beta=0.27$, $p<0.05)$. Teacher teaching experience had a significant direct relationship with their beliefs about the positive impacts of inclusive education on non-disabled children's understanding of their peers with disabilities $(\beta=0.20, p<0.05)$ and on disabled children's social $(\beta=0.35, p<0.05)$ and cognitive ( $\beta=0.30, p<0.05)$ development. Furthermore, the teachers' beliefs about the positive effects of inclusive education on disabled children's cognitive development and non-disabled children's understanding of 
disabled peers in turn enhanced teachers' self-efficacy in inclusive education $(\beta=0.31$ and $\beta=0.58$, $p<0.05$, respectively).

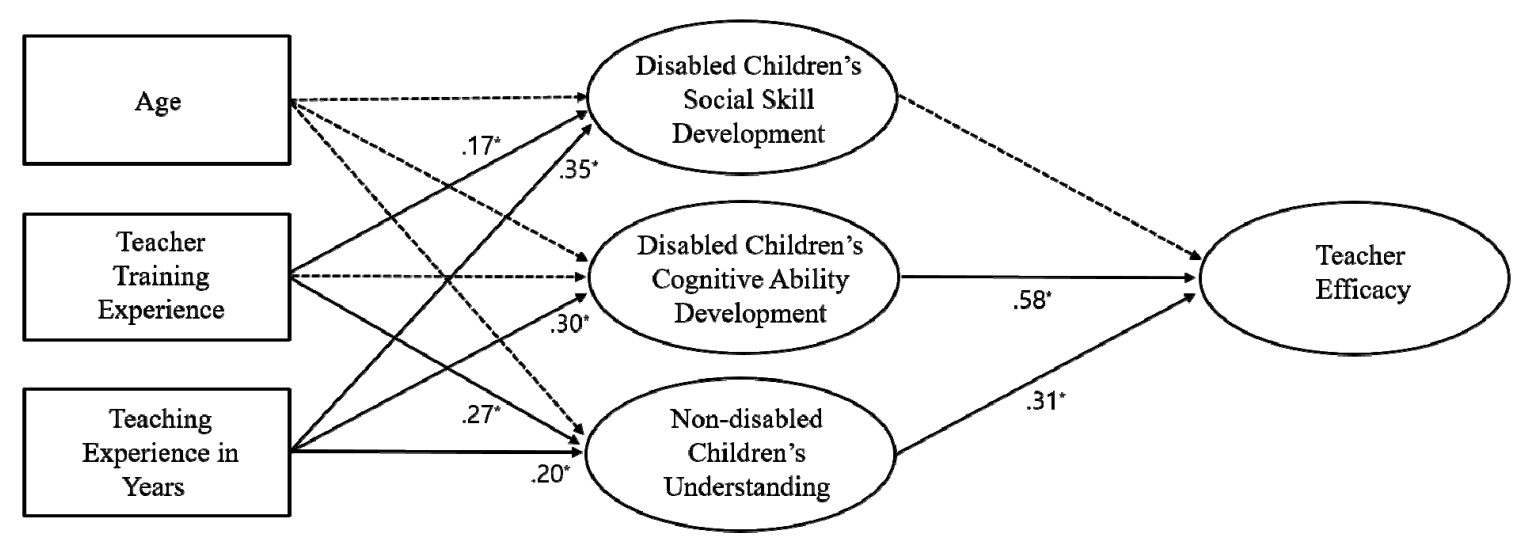

Figure 2. Final structural model with standardized solution. Note. ${ }^{*} p<0.05$; significant path coefficients are shown in bold line; dotted line = non-significant.

\section{Discussion}

The literature reported that learning in inclusive classrooms has positive values for both children with and without disabilities. These studies emphasized teacher variables, especially their attitudes towards inclusive education and self-efficacy running these classes, as important factors determining the successful implementation of inclusive education [8,13]. Therefore, this study used a sample of Korean nursery teachers to investigate the relationships between teachers' demographic and educational backgrounds, their beliefs about the positive outcomes of inclusive education, and their self-efficacy as regards implementing inclusive education.

Teachers with more training experience tended to show more positive beliefs towards the influence of inclusive education on children with and without disabilities. More specifically, teachers with more training experience had a stronger belief in the positive influence of inclusive education on disabled students' social development and on non-disabled students' ability to understand their disabled peers. However, there was no significant difference in the beliefs about the positive effects of inclusive education on disabled students' cognitive development between teachers with more training experience and those with less. Additionally, teachers with more teaching experience were more likely to believe that inclusive education leads to positive changes in terms of non-disabled students' understanding of their disabled peers' needs, as well as disabled students' social and cognitive development. These results were inconsistent with previous studies reporting that years of teaching experience appeared not to be a critical factor in teachers' attitudes towards inclusion in South Korea [36,49].

In the current study, both training and teaching experiences were positively associated with teachers' positive perceptions about inclusive education, which was similar to previous findings that teaching and training experiences significantly affected teachers' perception of inclusive education [6,19]. However, only teaching experience, not training experience, had a significant relationship with teachers' beliefs about the positive impacts of inclusive education on disabled children's cognitive development. This finding suggests that the direct interaction with students with disabilities and the hands-on experience of teaching those students are needed to believe in the positive impacts of inclusive education on disabled students' cognitive development. These results support the argument made by previous studies that teachers with more direct interactions with children with disabilities during their training are more likely to support inclusive education $[20,50]$. Institutional measures, such as teacher training, teachers' workshops, practical training for the teachers, and the publication of teaching guidance, may support teachers to acquire relevant knowledge about the development of disabilities and teaching methods through practical interaction 
with children with disabilities before they enter into inclusive educational settings. This study suggests that these experiences can enable the teachers to establish a positive perception of inclusive education and, thereby, enhance their self-efficacy, which is needed for the effective implementation of inclusive education.

Teachers' positive beliefs about inclusive education were in turn significantly related to their self-efficacy in teaching, supporting their mediating effects on the relationship between teacher background factors and self-efficacy. These findings were consistent with previous studies $[9,38]$ suggesting that when teachers had more teaching experiences and knowledge and skills in inclusive education, they were more likely to report positive beliefs toward inclusive education and higher self-efficacy. However, whereas teachers' beliefs regarding the positive influences of inclusive education on disabled students' social development were not associated with teacher self-efficacy, their beliefs regarding the positive influences of inclusive education on disabled students' cognitive development and non-disabled students' understanding of their disabled peers were significantly, positively associated with teacher self-efficacy. More than half of the Korean teachers in Hwang and Evan's study [51] reported that demands for academic outcomes make inclusion more difficult. These results indicate that when teachers are uncertain about inclusive education's positive impacts on students' cognitive and knowledge development, their self-efficacy regarding inclusive education is likely to be low. Although further investigation is necessary to understand these differential outcomes, the current study's findings provide new insights into contributing factors to teacher self-efficacy.

Teacher age did not have any significant direct or indirect relationship with their beliefs towards inclusive education or with self-efficacy. In other words, although the amount of training and teaching experiences significantly differentiated teachers' perceptions about inclusive education and their level of self-efficacy, there was no significant difference between younger and older teachers as regards to their perceptions about inclusive education or their level of self-efficacy. These outcomes were inconsistent with previous studies in South Korea suggesting that teacher age was an important determinant of teacher attitudes toward inclusive education [51]. Specifically, previous studies reported that the older the teachers, the more negative their attitudes towards inclusion, and explained that younger teachers might have been exposed to more professional experience with inclusion. However, this study's finding was consistent with other studies reporting that teacher's age did not have a significant relationship with their view on inclusive education $[6,25]$. Therefore, further studies are needed to better understand the interactions between teacher demographic and background factors.

Despite the many strengths of the present study, some important limitations should be considered when interpreting its results. The current study's findings are based on a survey of teachers working in nursery centers in Seoul, limiting the generalizability of findings. It is suggested that future studies include diverse samples from both rural and urban contexts and different cultural backgrounds. In addition, age, training experience, and teaching experience were examined as teacher background factors. Although meaningful information could be obtained using these variables, future studies are likely to identify additional, more diverse teacher and institutional factors, such as class size and administrative support, that can influence teachers' beliefs about inclusive education and self-efficacy. These additional studies will help researchers and school administrators develop and evaluate methods to improve teachers' ability to effectively serve students with and without disabilities.

\section{Conclusions}

Discussion, research, and attention have all been focused worldwide on the importance and effectiveness of inclusive education. However, in South Korea, controversies continue over the benefits of inclusive education, even among teachers leading inclusive education classrooms. Their critical evaluation of the current status of inclusive education holds that practical, systematic strategies have not yet been developed for teachers to effectively implement inclusive education, which influences their efficacy in teaching students in inclusive settings. Teacher self-efficacy has been reported in the literature as one of the most significant indicators of the successful implementation of inclusive 
education. Therefore, the current study aimed to identify factors that contribute to teacher self-efficacy to improve the education provided to children both with and without disabilities and to provide a foundation for the sustainability of inclusive education in South Korean education.

This study analyzed and confirmed the mediating impacts of teachers' beliefs toward the positive effects of inclusive education on the relationship between teachers' background variables and their self-efficacy. Given that teacher self-efficacy is related to positive educational outcomes [34], school administrators and policy makers should consider developing ways to improve teachers' beliefs about the beneficial outcomes of inclusive education for students with and without disabilities. The current study suggests that when teachers, irrespective of their age, receive sufficient teaching and training experiences related to supporting children with disabilities, they tend to believe in inclusive education and their ability to serve all students in inclusive classrooms. Therefore, it is suggested that a systematic support system be developed to help teachers enhance their knowledge and skills and positive beliefs towards inclusive education, as such a system is likely to ultimately lead to the successful implementation of inclusive education.

Author Contributions: Conceptualization, writing-original draft, S.Y.; data curation, methodology, E.K.; formal analysis, writing — review and editing, K.S.

Funding: This work was partially supported by the Hankuk University of Foreign Studies Research Fund.

Conflicts of Interest: The authors declare that they have no conflict of interest.

Appendix A. Teacher Beliefs towards Inclusive Education Scale

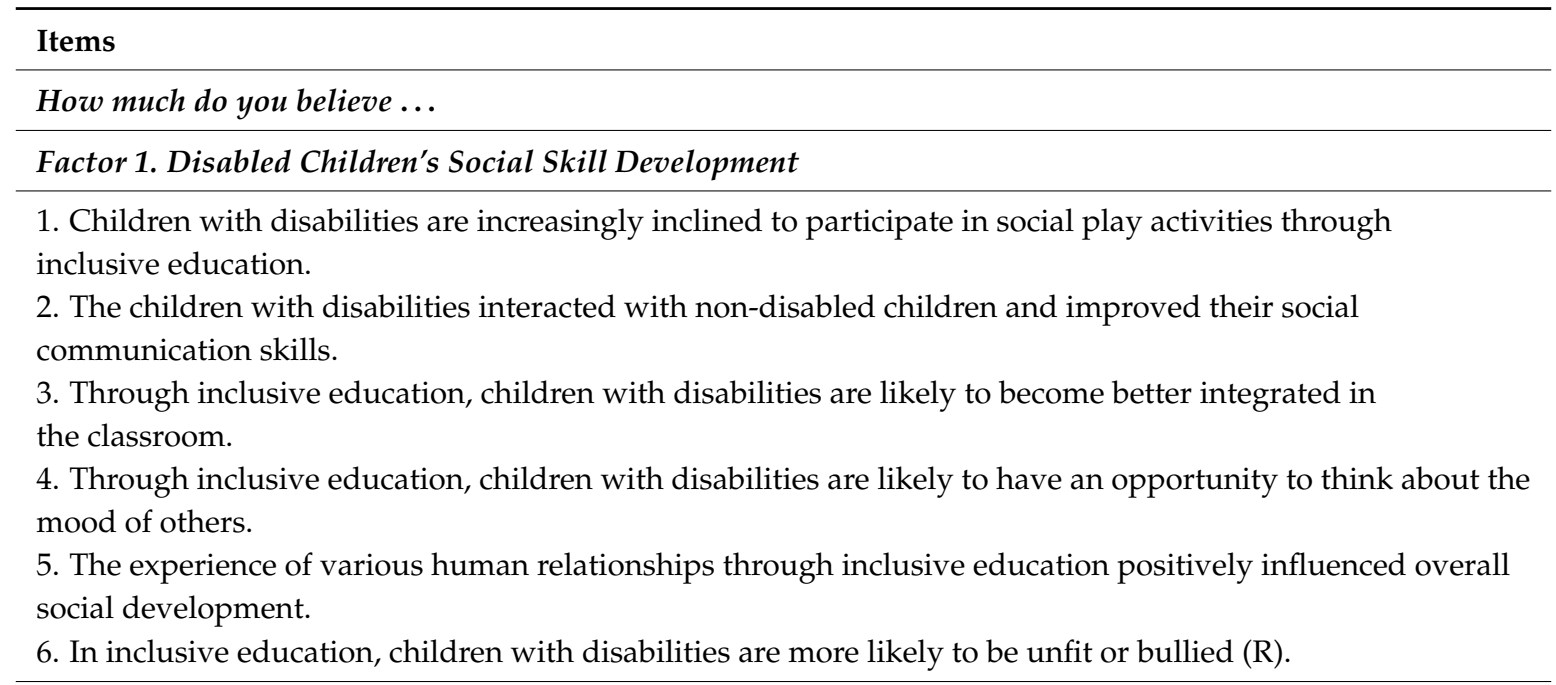

Factor 2. Disabled Children's Cognitive Ability Development

1. The demonstration of appropriate responses and activities of non-disabled children have been a stimulant for promoting the cognitive learning of children with disabilities.

2. In inclusive education, children with disabilities are more likely to fall behind because they do not have adequate learning guidance.

3. Through inclusive education, children with disabilities are able to challenge and participate in learning.

4. Adaptive behavior learning of children with disabilities was improved through proper response and demonstration of non-disabled children in inclusive education.

5. Through inclusive education, children with disabilities have improved mimicking skills.

6. I believe that inclusive education can significantly affect disabled children's cognitive abilities. 


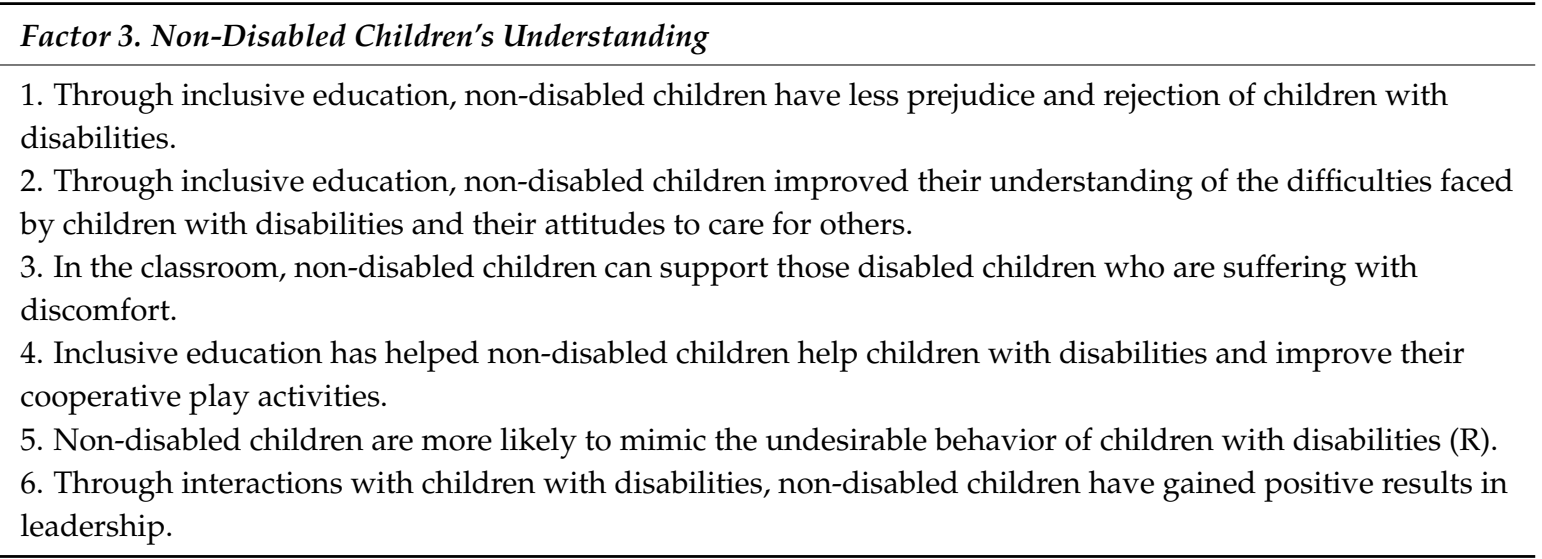

\section{References}

1. Inclusion International. Inclusion: Myths and Misconceptions; Inclusion International: London, UK, 2018.

2. De Boer, A.; Pijl, S.J.; Minnaert, A. Regular primary school teachers' attitudes towards inclusive education: A review of the literature. Int. J. Incl. Educ. 2011, 15, 331-353. [CrossRef]

3. Porter, G.L.; Towell, D. Advancing Inclusive Education: Keys to Transformational Change in Public Education Systems; Inclusive Education Canada (IEC): Toronto, ON, Canada, 2017.

4. Lee, T.S.; Kim, T.J. The awareness compared of inclusive classroom teachers' instructional adaptation on inclusive education valuables. Korean J. Incl. Educ. 2012, 7, 101-121.

5. Nam, H.J.; Park, S. Effects of a diversity education program on the students' empathy ability, cultural sensitivity and disabilities acceptance beliefs in an inclusive elementary school. Spec. Educ. Res. 2014, 13, 53-76. [CrossRef]

6. Tiwari, A.; Das, A.; Sharma, M. Inclusive education a "rhetoric" or "reality"? Teachers' perspectives and beliefs. Teach. Teach. Educ. 2015, 52, 128-136. [CrossRef]

7. Geerlings, J.; Thijs, J.; Verkuyten, M. Teaching in ethnically diverse classrooms: Examining individual differences in teacher self-efficacy. J. Sch. Psychol. 2018, 67, 134-147. [CrossRef] [PubMed]

8. Zee, M.; Koomen, H.Y. Teacher self-efficacy and its effects on classroom processes, student academic adjustment, and teacher well-being: A synthesis of 40 years of research. Rev. Educ. Res. 2016, 86, 981-1015. [CrossRef]

9. Specht, J.; McGhie-Richmond, D.; Loreman, T.; Mirenda, P.; Bennett, S.; Gallagher, T.; Young, G.; Metsala, J.; Aylward, L.; Katz, J.; et al. Teaching in inclusive classrooms: Efficacy and beliefs of Canadian preservice teachers. Int. J. Incl. Educ. 2016, 20, 1-15. [CrossRef]

10. Malinen, O.; Savolainen, H.; Xu, J. Beijing in-service teachers' self-efficacy and beliefs towards inclusive education. Teach. Teach. Educ. 2012, 28, 526-534. [CrossRef]

11. Vaz, S.; Wilson, N.; Falkmer, M.; Sim, A.; Scott, M.; Cordier, R.; Falkmer, T. Factors associated with primary school teachers' beliefs towards the inclusion of students with disabilities. PLoS ONE 2015, 10, e0137002. [CrossRef] [PubMed]

12. Lee, M. Pre-service teachers' perception of inclusion based on their personal experiences of inclusion as students. J. Rehabil. Psychol. 2017, 24, 279-296.

13. Sharma, U.; Shaukat, S.; Furlonger, B. Attitudes and self-efficacy of pre-service teachers towards inclusion in Pakistan. J. Res. Spec. Educ. Needs 2015, 15, 97-105. [CrossRef]

14. Sailor, W.S.; McCart, A.B. Stars in alignment. Res. Pract. Persons Severe Disabl. 2014, 39, 55-64. [CrossRef]

15. Special Education Annual Report; South Korea Ministry of Education, Science and Technology: Seoul, Korea, 2018.

16. Kim, Y.W. Inclusive education in Korea: Policy, practice, and challenges. J. Policy Pract. Intellect. Disabil. 2013, 10, 79-81. [CrossRef]

17. Savolainen, H.; Engelbrecht, P.; Nel, M.; Malinen, O. Understanding teachers' beliefs and self-efficacy in inclusive education: Implications for pre-service and in-service teacher education. Eur. J. Spec. Needs Educ. 2012, 27, 51-68. [CrossRef] 
18. Park, J.B. Secondary reserve teachers' recognition of inclusive education. Spec. Educ. Res. 2012, 11, 171-188. [CrossRef]

19. Waitoller, F.R.; Artiles, A.J. A decade of professional development research for inclusive education: A critical review and notes for a research program. Rev. Educ. Res. 2013, 83, 319-356. [CrossRef]

20. Lancaster, J.; Bain, A. The design of pre-service inclusive education courses and their effects on self-efficacy: A comparative study. Asia-Pac. J. Teach. Educ. 2010, 38, 117-128. [CrossRef]

21. Lee, F.L.M.; Yeung, A.S.; Tracey, D.; Barker, K. Inclusion of children with special needs in early childhood education: What teacher characteristics matter. Top. Early Child Spec. Educ. 2015, 35, 79-88. [CrossRef]

22. Kim, M.J.; Chung, K.S. Relationships among the teacher's factors, professional learning environments and inclusive empowerment of teacher in inclusive child care center. Korean J. Child. Care Educ. 2012, 67, $19-42$.

23. Carroll, A.; Forlin, C.; Jobling, A. The impact of teacher training in special education on the attitudes of Australian preservice general educators towards people with disabilities. Teach. Educ. Q. 2003, 30, 65-79.

24. Schmidt, M.; Vrhovnik, K. Attitudes of teachers towards the inclusion of children with special needs in primary and secondary schools. Hrvatska Revija za Rehabilitacijska Istraživanja 2015, 51, 16-30.

25. Lee, H.M.; Kang, Y.S.; Jung, H.Y. Early childhood teacher's efficacy AND influential factors about inclusive education in inclusive education institutions for disabled preschoolers. J. Spec. Educ. Rehabil. Sci. 2016, 55, 371-389. [CrossRef]

26. Song, J. Inclusive education in Japan and Korea: Japanese and Korean teachers' self-efficacy and attitudes towards inclusive education. J. Res. Spec. Educ. Needs 2016, 16, 643-648. [CrossRef]

27. Kim, J.H.; Cho, Y.T. Qualitative research on the recognition of kindergarten teachers on effects of inclusive education of the disabled infants. Korean J. Incl. Educ. 2008, 3, 27-44.

28. Bandura, A. Guide to the construction of self-efficacy scales. In Self-Efficacy Beliefs of Adolescents; Pajares, F., Urdan, T., Eds.; IAP—Information Age Publishing: Greenwich, CT, USA, 2006; Volume 5, pp. 307-337.

29. Fackler, S.; Malmberg, L.E. Teachers' self-efficacy in 14 OECD countries: Teacher, student group, school and leadership effects. Teach. Teach. Educ. 2016, 56, 185-195. [CrossRef]

30. Schunk, D.H.; DiBenedetto, M.K. Self-efficacy theory in education. Handb. Motiv. Sch. 2016, 2, 34-54. [CrossRef]

31. Tschannen-Moran, M.; Hoy, A.W. Teacher efficacy: Capturing and elusive construct. Teach. Teach. Educ. 2001, 17, 783-805. [CrossRef]

32. Sharma, U.; Loreman, T.; Forlin, C. Measuring teacher efficacy to implement inclusive practices. J. Res. Spec. Educ. Needs 2012, 12, 12-21. [CrossRef]

33. Sharma, U.; Sokal, L. The impact of a teacher education course on pre-service teachers' beliefs about inclusion: An international comparison. J. Res. Spec. Educ. Needs 2015, 15, 276-284. [CrossRef]

34. Jeong, H.; Tyler-Wood, T.L.; Kinnison, L.; Morrison, G. The US and South Korean pre-k through 6 teachers' beliefs about inclusion practices in their countries: Cross cultural perspectives. J. Int. Assoc. Spec. Educ. 2015, $15,11-23$.

35. Lohrmann, S.; Barnbara, L.M. Elementary education teacher's beliefs about essential supports needed to successfully include students with developmental disabilities who engage in challenging behaviors. Res. Pract. Persons Severe Disabl. 2006, 31, 157-173. [CrossRef]

36. Choi, S.-M. A Study on Daycare Teachers' Perception of the Effects of Inclusive Education. Master's Thesis, The Graduate School of Education, Hankuk University of Foreign Studies, Seoul, Korea, 2014.

37. Hong, A.E.; Hur, Y.S.; Lee, H.S. A study of kindergarten teachers' belief and efficacy toward inclusive education of young children with developmental delay. J. Spec. Educ. Rehabi. Sci. 2009, 48, 183-209.

38. Specht, J.A.; Metsala, J.L. Predictors of teacher efficacy for inclusive practice in pre-service teachers. Except. Educ. Int. 2018, 28, 67-82.

39. Han, H. Experience-based factors influencing perceptions and beliefs of pre-service early childhood education teachers toward inclusive education for young children with disabilities. Korean J. Early Child. Educ. Care 2006, 9, 77-99.

40. Park, Y.-J.; Cho, K.-S. Perceptions on the effectiveness of inclusion of young children with disabilities among early childhood education and early childhood special education teachers. Korean J. Early Child. Spec. Educ. 2003, 3, 43-66. 
41. Nam, G.-H. Effects of Inclusion on Teachers and Students in Preschool Setting. Master's Thesis, Department of Early Childhood Special Education, Graduate School of Special Education, Kongju National University, Kongju, Chungcheongnam-do, Korea, 2010.

42. Son, J.Y. The effectiveness of teacher education using video materials on pre-service teachers' attitude and efficacy of inclusive education. Korean J. Teach. Educ. 2012, 28, 225-246.

43. Boomsma, A. Nonconvergence, improper solutions, and starting values in LISREL maximum likelihood estimation. Psychometrika 1985, 50, 229-242. [CrossRef]

44. Nunnally, J.C. Psychometric Theory; McGraw-Hill: New York, NY, USA, 1967.

45. Bentler, P.M.; Bonett, D.G. Significance tests and goodness of fit in the analysis of covariance structures. Psychol. Bull. 1980, 88, 588-606. [CrossRef]

46. Bentler, P.M. Comparative fit indexes in structural models. Psychol. Bull. 1990, 107, 238-246. [CrossRef] [PubMed]

47. Steiger, J.H.; Lind, J.C. Statistically based tests for the number of common factors. Presented at The Annual Meeting of the Psychometric Society, Iowa, IA, USA; 1980.

48. Curran, P.J.; West, S.G.; Finch, J.F. The robustness of test statistics to nonnormality and specification error in confirmatory factor analysis. Psychol. Methods 1996, 1, 16. [CrossRef]

49. Bentley-Williams, R.; Morgan, J. Inclusive education: Pre-service teachers' reflexive learning on diversity and their challenging role. Asia-Pac. J. Teach. Educ. 2013, 41, 173-185. [CrossRef]

50. Weiner, H.M. Effective inclusion: Professional development in the context of the classroom. Teach. Except. Child. 2003, 35, 12-18. [CrossRef]

51. Hwang, Y.; Evans, D. Attitudes towards inclusion: Gaps between beliefs and practice. Int. J. Spec. Educ. 2011, $26,136-146$.

(C) 2019 by the authors. Licensee MDPI, Basel, Switzerland. This article is an open access article distributed under the terms and conditions of the Creative Commons Attribution (CC BY) license (http:/ / creativecommons.org/licenses/by/4.0/). 